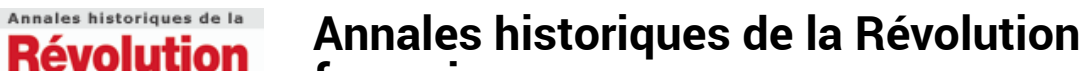

française française

324 | avril-juin 2001

Louis Charles Antoine Desaix. Officier du roi, Général de la République

\section{Émancipation, réforme, Révolution. Hommage à Marita Gilli.}

\section{Michel Biard}

\section{(2) OpenEdition Journals}

Édition électronique

URL : https://journals.openedition.org/ahrf/1119

DOI : $10.4000 /$ ahrf. 1119

ISSN : 1952-403X

Éditeur :

Armand Colin, Société des études robespierristes

Édition imprimée

Date de publication : 1 juin 2001

Pagination : 208-210

ISSN : 0003-4436

Référence électronique

Michel Biard, «Émancipation, réforme, Révolution. Hommage à Marita Gilli. », Annales historiques de la Révolution française [En ligne], 324 | avril-juin 2001, mis en ligne le 21 avril 2004, consulté le 24 avril 2022. URL : http://journals.openedition.org/ahrf/1119; DOI : https://doi.org/10.4000/ahrf.1119

Ce document a été généré automatiquement le 24 avril 2022.

Tous droits réservés 


\title{
Émancipation, réforme, Révolution. Hommage à Marita Gilli.
}

\author{
Michel Biard
}

\section{RÉFÉRENCE}

Émancipation, réforme, Révolution. Hommage à Marita Gilli, Besançon, Presses universitaires franc-comtoises, 2000, $537 \mathrm{p}$.

1 Ce bel ouvrage rassemble des chercheurs venus de disciplines et de pays divers pour, au-delà de l'hommage à leur collègue, s'interroger autour de trois axes qui ont été des thèmes de prédilection pour Marita Gilli. Les contributions couvrent une très large période, du xviie siècle à l'époque la plus contemporaine. Pour l'essentiel, le siècle des Lumières est représenté par quelque 220 pages avec d'une part un regard croisé sur la France et l'«Allemagne», d'autre part une approche de la Révolution française et de «ses résonances».

2 Trois contributions évoquent le lent cheminement vers l'émancipation féminine, deux d'entre elles prenant l'exemple d'une œuvre littéraire. A. Guedj remet à jour une pièce peu connue de Marivaux, La Colonie, relue à la lumière d'un texte de Poulain de la Barre (De l'Égalité des deux sexes), tandis que F. Jacob a choisi de revenir sur le plus classique Paul et Virginie pour évoquer une «impossible émancipation» (avec, in fine, le sacrifice du corps de Virginie, la bien-nommée, le refus du don complet de soi, le refus de livrer le «sanctuaire de sa pudeur», l'impossibilité d'échapper à son cadre, fût-ce pour l'amour de l'autre). Difficile cheminement vers l'émancipation du sexe présumé «faible» que confirme M. Cubells à la lecture attentive de deux plaidoyers anonymes pour les femmes dans la Provence des premiers mois de 1789. Les Réclamations des femmes de Provence (...) et le Cahier des représentations et doléances du beau sexe (...) sont en effet loin des audaces d'une Olympe de Gouges. Si le rôle politique des femmes est certes revendiqué ( ... les femmes sont aussi capables de bien gouverner que les 
hommes.»), l'image de la femme reste très convenue avec un éloge de la bonne épouse et une morale que ne renierait parfois guère le clergé le plus conservateur!

Quatre textes sont consacrés, pour cette partie, aux espaces germaniques chers à Marita Gilli, avec une nette tendance à privilégier les liens culturels entre Français et Allemands. Liens qui conduisent aux interrogations de C.F. Bahrdt sur la Bible (qui aboutissent, d'après D. Minary, «aux rives [...] de l'irréligion [...]»), aux écrits de J.G. Herder, influencé nettement par Montesquieu dans sa réflexion sur le «lien dialectique entre universalisme et particularisme» (J. Mondot), sans oublier bien sûr la tradition du voyage intellectuel qui fait découvrir l'autre (avec ici l'exemple, développé par F. Knopper, des enseignements donnés en la matière par J. D. Michaelis à l'université de Göttingen). La transition avec la partie dévolue à la Révolution française est assurée par la contribution de H. Boulay sur le Politisches Journal que publie G.B. von Schirach de 1781 à 1804 . Toute l'ambiguïté du regard étranger sur la Révolution française s'y trouve avec cet homme qui commence par revendiquer une liberté de la presse susceptible d'encourager l'Aufklärung avant, sous l'influence des échos venus d'outre-Rhin, de suggérer que soient posées des barrières afin que Pressfreyheit ne se mue point en Pressfrechtheit (insolence de la presse)!

Cette Révolution française, à laquelle Marita Gilli a consacré de très importants travaux (il suffit, pour qui voudrait encore s'en convaincre, de se reporter à la liste de ses écrits aux pages 15 à 32), occupe environ 140 pages qui s'ouvrent avec une contribution d'E. Lemay sur les «non-intervenants» à l'Assemblée constituante, cette majorité silencieuse avant la lettre qui regroupe environ la moitié des députés. L'auteur nous livre leur signalement collectif (qui ne se singularise guère par rapport à l'ensemble des députés, ce qui n'est en soi guère étonnant) avant de s'interroger sur leur «utilité» politique (les travaux auraient-ils avancé plus vite sans cette masse qui ne fait guère que chuchoter et... voter!). R. Monnier choisit pour sa part une plume davantage qu'un orateur en la personne de Condorcet dont les écrits, de 1789 à 1794, sont passés au crible afin de repérer les notions d'Égalité et de Liberté (l'Égalité s'affirmant, au terme de l'étude, comme «un des mots forces de son discours»).

Loin de la tragédie réelle vécue par Condorcet au printemps 1794, R. Barny analyse le déclin (relatif) de la tragédie dans les théâtres de la capitale (de 1789 à 1795), le «mélange des genres» conduisant des œuvres annoncées comme des tragédies vers le mélodrame tandis que devient fréquente la réduction des pièces de cinq à trois actes (on notera ici une précieuse annexe à cette contribution qui fournit la liste des œuvres avec le nombre des représentations, nombre tout de même rendu quelque peu aléatoire par le fait que peu de journaux ont été utilisés par l'auteur).

$6 \quad$ Il va de soi que les regards allemands sur la Révolution française prennent une fois encore une place importante dans ce volume. Le texte de J. Moes est particulièrement intéressant par le fait que justement il croise tout à la fois les deux nations (avec l'émigration française en 1792) et deux regards (celui de Goethe dans la Campagne de France, celui de Chateaubriand dans les Mémoires d'outre-tombe). La comparaison est riche en diversité avec un Goethe (qui n'est qu'observateur) qui décrit une émigration somme toute facile et des rapports parfois tendus avec les populations locales là où Chateaubriand (qui, lui, émigre et compte bien en découdre avec les troupes françaises) peint les chemins détournés et la traversée des champs de blés ou encore de bons rapports entre émigrés et "pays d'accueil»! Tous deux s'accordent sur un point: l'insouciance, la certitude (initiale) des émigrés d'être bien vite de retour sur les bords 
de la Seine... Deux autres contributions sont consacrées à des regards allemands sur la Révolution, celui de C. A. Fischer qui bascule d'une «vision idéale» vers la condamnation des excès révolutionnaires (A. Ruiz) et celui de A. G. F. Rebmann qui alterne espoirs et déceptions vis-à-vis de la politique rhénane du Directoire (P. A. Bois).

7 Souvent passionnantes sont enfin les contributions qui analysent les héritages (plus ou moins lointains) de la Révolution française, les réflexions de Napoléon dans son exil au fin fond de l'Atlantique sud (A. Casanova), la mort de Danton de Büchner relue par C. Tatu ou encore le trop peu connu Chemin de France de Jules Verne écrit en 1887 avec "ce qu'il est de bon ton de garder dans l'optique de la Troisième République» (F. Montaclair). En prise avec les déchirements du xxe siècle, deux textes se singularisent: celui de J. Guilhaumou qui évoque une nouvelle fois les liens entre la Révolution française et les mouvements sociaux qu'a connus récemment la France, liens qui l'amènent à évoquer une «éthique de l'émancipation»; plus encore la contribution passionnante de F. Genton qui met à jour les écrits d'une femme injustement tombée dans l'oubli, Gertrud Kolmar. Juive allemande, elle se passionne pour le robespierrisme alors que l'étau nazi se resserre; elle réalise un Portrait de Robespierre, deux poésies consacrées à l'Incorruptible, une pièce de théâtre intitulée Cécile Renault et un cycle de 45 ballades intitulé Robespierre, toutes œuvres écrites entre l'été 1933 et le printemps 1935. F. Genton rappelle à juste titre qu'il est bien facile de jeter la pierre à un «aveuglement robespierriste» qui sublime le martyre final pour mieux faire oublier la Terreur. Replacée dans son contexte et dans son destin tragique (elle meurt à Auschwitz), Gertrud Kolmar donne assurément à penser et ce qui vient alors à l'esprit des héritages de 1789 comme de l'an II est bien cette nécessaire esthétique de la résistance superbement développée par Peter Weiss. 